\title{
Desenvolvimento de ferramenta de chatbot como solução para a comunicação do IFB
}

\author{
Katlen K. C. Silva ${ }^{1}$, Rodrigo O. Tierno ${ }^{1}$, Sandra M. Branchine ${ }^{1}$, \\ Douglas Santos S. Vilaça ${ }^{1}$, Fábio Henrique M. Oliveira ${ }^{1}$ \\ ${ }^{1}$ Instituto Federal de Educação, Ciência e Tecnologia de Brasília - Campus Brasília \\ Setor de Grandes Áreas Norte 610 - Asa Norte - 70830-450 - Brasília - DF - Brasil \\ \{katlen.cost, rodrigo.tierno14\}@gmail.com, \\ \{sandra.branchine, douglas.vilaca, fabio.oliveira\}@ifb.edu.br
}

\begin{abstract}
Resumo. Por meio de uma pesquisa, foi identificado que grande parte dos estudantes do IFB já perdeu alguma oportunidade em não ter acesso à notícias em tempo. Este trabalho tem como público-alvo instituições de ensino, estudantes e desenvolvedores de sistemas. E nele foi desenvolvido um chatbot baseado em regras a fim de otimizar a forma como os estudantes do IFB acessam às informações e notícias do portal oficial da instituição.
\end{abstract}

\section{Introdução}

Chatbot é um sistema de conversação capaz de interagir com usuários ou outros sistemas processando linguagem natural ou usando elementos de interface. Ele pode ser baseado em regras, em que a entrada do usuário deve seguir uma padronização imposta pelo sistema, ou pode ser inteligente, construído de forma a gerar respostas de acordo com o contexto da conversa [Kar and Haldar 2016]. No Brasil, por exemplo, em 2018, o Magazine Luíza e o Banco do Brasil lançaram chatbots com o objetivo de auxiliar seus clientes analisando, interpretando e respondendo às perguntas por eles feitas.

Dentre os diversos meios de comunicação do IFB (Instituto Federal de Brasília), o principal deles é o portal IFB (ifb.edu.br), que funciona como uma página web tradicional. Uma pesquisa feita em abril de 2020 em parceria com a Diretoria de Comunicação Social (DICOM), em que uma amostra de 1.789 estudantes, revelou que para 57,1\% dos participantes, o portal IFB é o mais usado para a busca de informações sobre a instituição. O portal tem as notícias de cada campus que são atualizadas a todo momento sem haver qualquer tipo de notificação à comunidade. Neste formato, o usuário não recebe a informação, mas precisa buscar por ela. A pesquisa mencionada também evidenciou que $45,1 \%$ dos estudantes que participaram da pesquisa já perderam oportunidades e/ou editais porquê não souberam a tempo. Este dado destaca a necessidade do IFB em adotar uma comunicação ativa.

Dentro desse contexto, este trabalho propõe o desenvolvimento de um chatbot baseado em regras para auxiliar a comunidade do IFB. Essa ferramenta irá buscar dentro do portal IFB os resultados para as solicitações feitas pelos seus usuários.

\section{Materiais e métodos}

Para o desenvolvimento deste trabalho foram realizadas pesquisas com o usuário e feita a definição das tecnologias e ferramentas a serem utilizadas. 


\subsection{Pesquisa com o usuário}

Na primeira pesquisa, de levantamento de dados foi elaborado um formulário, composto por 11 questões com o objetivo de identificar como os estudantes consomem as informações do Instituto Federal de Brasília. Esse levantamento recebeu 1.789 respostas de estudantes de todos os campi do IFB; a segunda pesquisa, de avaliação preliminar $^{1}$, foi elaborado, também, um formulário formado por 10 questões visando capturar o feedback de uso dos usuários reais do chatbot, bem como informações sobre a familiaridade com esse tipo de tecnologia. Essa avaliação ficou disponível dentro do chatbot por 17 dias e contou com 30 respostas; e na última pesquisa, de avaliação de usabilidade ${ }^{2}$, foram utilizados os conceitos e técnicas da ISO 9241-11. Por meio de um formulário composto por tarefas relacionadas ao contexto do IFB. Durante a avaliação, 12 usuários foram acompanhados individualmente em uma reunião pelo Google Meet, e nela eles executaram as tarefas propostas dentro do chatbot. O processo de avaliação de cada usuário durou em torno de 20 minutos no qual foi possível observar grande facilidade e receptividade na execução das tarefas.

\subsection{Chatbot}

Para este trabalho, foi desenvolvido um chatbot de domínio fechado, já que o objetivo é auxiliar os usuários quanto à questões inseridas dentro do contexto institucional, e baseado em regras no qual as interações do usuário com o bot são limitadas a comandos e botões, tornando a comunicação mais simples e direta.

\subsection{Telegram e TelegramBotAPI}

Telegram é uma plataforma de troca de mensagens em tempo real, para a escolha do uso do telegram, os seguintes parâmetros foram considerados: gratuidade, ferramentas e flexibilidade para a programação de chatbots. A biblioteca PyTelegramBotAPI é uma implementação da Bot API (interface criada para construir bots no Telegram), voltada para a programação em Python e foi utilizada para desenvolver o chatbot deste trabalho.

\subsection{Coleta de dados}

A fim de automatizar o processo de coleta de dados em uma página web é comumente adotada a técnica de web scrapping, que consiste em um programa que procura por dados em uma página da web e faz a coleta deles convertendo-os em dados estruturados para posterior análise [Vargiu and Urru 2013]. Neste trabalho, a web scrapping foi utilizada com o objetivo de coletar notícias a respeito dos campi e de processos seletivos no Portal IFB.

\subsection{Protótipo}

Para o desenvolvimento do protótipo ${ }^{3}$ do chatbot $^{4}$ foi feita a integração de todas as ferramentas e tecnologias levantadas na Seção 2. A Figura 1 mostra a proposta para essa integração que será detalhada a seguir.

\footnotetext{
${ }^{1}$ Avaliação preliminar: https : / / bit . ly/33Bzhko

${ }^{2}$ Convite para avaliação de usabilidade: https : / / bit. Iy/3vXqbeg

${ }^{3}$ Projeto no GitHub: https : / / github.com/infocbra/chatbot_ifb

${ }^{4}$ Chatbot no Telegram: https://t.me/ifb_informa_bot
} 


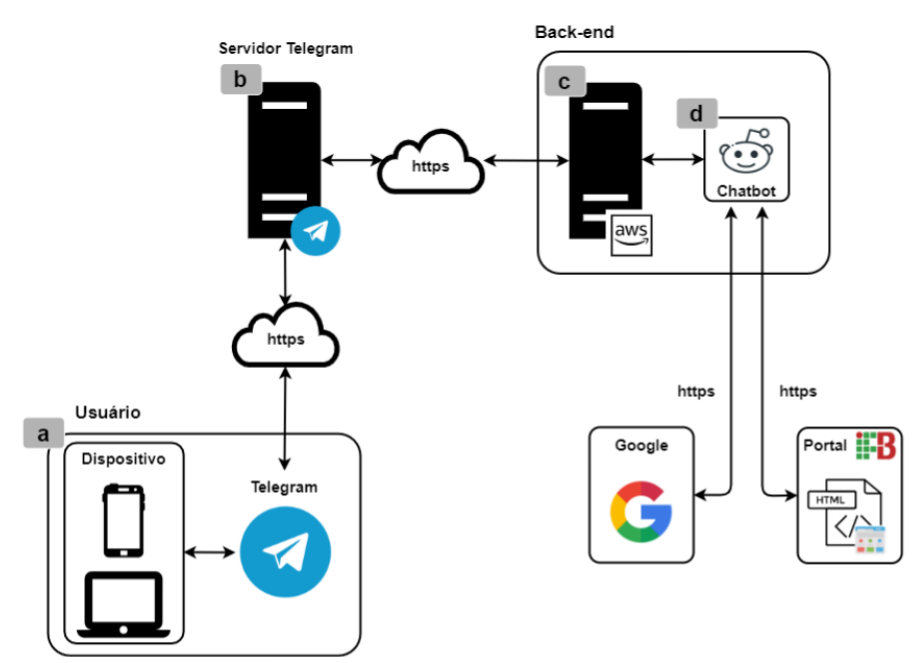

Figura 1. Organização dos elementos tecnológicos utilizados no trabalho.

Para acessar o chatbot o usuário precisa ter instalado o aplicativo Telegram ${ }^{5} \mathrm{em}$ seu dispositivo móvel ou desktop (Figura 1a). Ao iniciar uma conversa, a partir do comando /start, as atualizações de mensagens do chat são guardadas no servidor do Telegram onde está a interface Bot API (Figura 1b).

A aplicação do bot acessa as atualizações de mensagens do usuário, perguntando ao servidor se há atualizações, nesse caso o chatbot, que está em execução em um servidor da empresa Amazon (Figura 1c). Para o servidor de back-end, foi utilizada uma máquina virtual EC2 (Amazon Elastic Compute Cloud).

$\mathrm{Na}$ opção de busca personalizada é realizado a web scraping das informações diretamente na ferramenta de busca do Google. Já nas demais funcionalidades, a web scraping é realizada diretamente no portal IFB (Figura 1d).

\section{Resultados e discussões}

A DICOM é um setor sistêmico do Instituto Federal de Brasília que atende a todas as unidades do IFB, respondendo pela comunicação institucional. Buscando uma maneira de aumentar o alcance das informações à comunidade, foi realizado o levantamento de dados com os estudantes para entender sua situação em relação com o acesso à informação.

Mediante constatação das 1.789 devolutivas à pesquisa, foi proposta a criação de canais de comunicação ativa com serviço de mensagens instantâneas, disponível para smartphones, tablets e computadores. Após o planejamento e definição das atividades, foi desenvolvido o protótipo de chatbot, que encontra-se em funcionamento desde agosto de 2020.

Como resultado da implementação do chatbot (https://t.me/ifb_informa_bot), a Figura 2 apresenta o menu principal da ferramenta desenvolvida, em que estão dispostas as funcionalidades disponíveis aos usuários, definidas após o feedback coletado a partir da avaliação de usabilidade realizada em março de 2021 com participação de 12 voluntários.

Após implementado o chatbot, foi iniciada a fase de testes e de avaliação preli-

\footnotetext{
${ }^{5}$ Telegram: https://telegram.org/
} 
minar. Essa pesquisa revelou que $73 \%$ das pessoas que participaram já utilizou esse tipo de tecnologia para outras finalidades. Enquanto que 16,7\% delas já utilizou, mas pouco e $20 \%$ nunca utilizou. Já no que diz respeito a ter encontrado o que estava procurando utilizando o chatbot, a pesquisa revelou que a maioria, 96,7\% especificamente, teve sucesso na primeira tentativa.

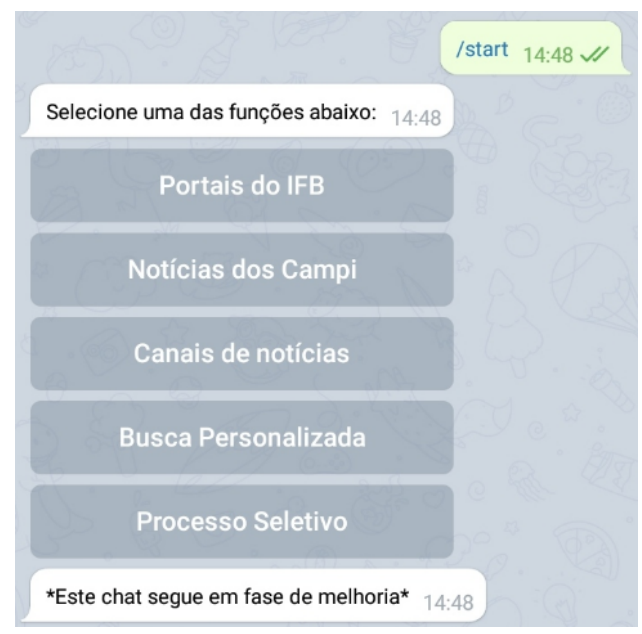

Figura 2. Menu principal do chatbot após feedback da avaliação de usabilidade.

A avaliação de usabilidade do sistema foi iniciada após a avaliação preliminar e ela foi feita a partir do modelo de especificação de usabilidade da ISO 9241-11, que conta com tarefas dadas ao usuário a fim de analisar o seu comportamento em contato com a ferramenta. O modelo foi adaptado ao chatbot desenvolvido neste trabalho, em que a medição da eficácia se deu na completude e acurácia com que o usuário finaliza a tarefa, a da eficiência se deu na quantidade de cliques e entrada de dados até a finalização de determinada tarefa e para medir a satisfação foi utilizada a Escala Likert [Likert 1932] com graus de satisfação desde muito insatisfeito até muito satisfeito. Durante a análise, foi possível notar pouca dificuldade na execução das tarefas em decorrência de falta de atenção no uso do chatbot. Mesmo assim, os usuários conseguiam contornar as situações e completar grande parte das tarefas mostrando adaptação no uso.

As pesquisas feitas com os usuários do chatbot apresentaram que a ferramenta desenvolvida tem potencial para atender ao que foi proposto, oferecendo uma alternativa para a busca por informações do IFB de maneira facilitada e ágil, até mesmo por pessoas que nunca tiveram contato anterior com sistemas similares. Além do grande potencial de chatbots no mercado, que são atrativos por alavancarem a entrega de valor ao usuário. Podendo ser aplicados em instituições de ensino públicas e privadas, objetivando a aproximação da comunicação institucional.

\section{Referências}

Kar, R. and Haldar, R. (2016). Applying chatbots to the internet of things: Opportunities and architectural elements.

Likert, R. (1932). A technique for the measurement of attitudes. Archives of Psychology.

Vargiu, E. and Urru, M. (2013). Exploiting web scraping in a collaborative filtering-based approach to web advertising. Artif. Intell. Research, 2:44-54. 